\title{
Sistema de Informações *
}

\author{
Alberto de Oliveira Lima Filho**
}

1. Sistema de Informações. 2. Informações. 3. Organização do Sistema. 4. Operação do Sistema.

Este comentário apresenta o anteprojeto de um sistema de informações, cujo objetivo central é o de operar, dirigir e controlar o processo de informações de uma emprêsa.

O anteprojeto abaixo especificado foi elaborado a partir de uma metodologia de trabalho que, em resumo, apresenta as seguintes fases:

1*. Análise, em conjunto com executivos, dos aspectos básicos e das peculiaridades do sistema de informações de uma emprêsa;

$2^{\text {a }}$. Análise de material bibliografico referente ao assunto e preparação de um esquema preliminar de trabalho para a estruturação do anteprojeto;

- A pesquisa relativa à preparação deste trabalho foi realizada junto a COMASP, agradecendo o autor a colaboração dos engenheiros CYRo BERNARDES e Emfllo BouER, da superintendencia de planejamento daquela emprêsa.

* * Professor-adjunto do Departamento de Mercadologia da Escola de Administração de Emprêsas de São Paulo, da Fundação Getúlio Vargas.

R. Adm. Emp., Rio de Janeiro, 10(2): 193-201, jul./set. 1970 
3a. Discussão com executivos a respeito do esquema preliminar do sistema de informações mais adequado aos objetivos operacionais da emprêsa;

$4^{\mathrm{a}}$. Elaboração do anteprojeto que consta dêste trabalho.

$O$ anteprojeto abaixo, em linhas gerais, encontra-se dividido em quatro itens principais dos quais constam subitens analíticos. Em sua essência, o anteprojeto procura definir o que é um sistema de informações e seus objetivos. A seguir, passa-se à análise das informações, sua classificação, coleta, processamento, codificação, arquivamento e retrieval.

O item seguinte examina a organização do sistema de informaç̃̃es, esquematizando programas para sua implementação.

O último item estuda e define métodos operacionais recomendados para operar o sistema de informaçóes sugerido no anteprojeto.

A fim de oferecer uma visão geral da estrutura proposta, especifica-se, abaixo, o roteiro do anteprojeto, objeto dêste comentário.

1. Sistema de Informações

1.1. Conceito

1.2. Objetivos

2. Informações

2.1. Classificação

2.2. Coleta

2.3. Processamento

2.4. Codificação

2.5. Arquivamento

2.6. Retrieval

3. Organização do Sistema

3.1. Programa de organização

3.2. Recursos humanos

3.3. Implementação

4. Operação do Sistema

4.1. Modêlo 


\subsection{Input de informações}

4.3. Output de informações

4.4. Operação e contrôle

Antes de passar ao desenvolvimento do anteprojeto, convém esclarecer que o mesmo foi concebido em função dos requisitos fundamentais da abordagem por sistemas, ou seja, parte da análise de variáveis, que compõem o sistema, examina suas interrelações e, posteriormente, estrutura-se o esquema operacional, mais adequado ao desempenho eficiente do processo de operação.

\section{Sistema de Informaçбes}

\subsection{CONCEITO}

O sistema de informações pode ser conceituado como um dos componentes da estrutura organizacional, através do qual é processado, de forma ordenada, o fluxo de comunicações internas e externas da emprêsa.

O sistema de informações, por definição, constitui também um sistema pelo qual são obtidos dados para as operações de contrôle e planejamento da emprêsa. Em síntese, o sistema de införmações gera dados de forma esquematizada e ordenada, os quais fornecem subsídios para o processo de tomada de decisões. Como decorrência imediata desta definição, nota-se que o sistema de informações recebe inputs que, após processados, transformamse em outputs, que são utilizados para a tomada de decisరés administrativas, as quais seriam mais arriscadas, sem que houvessem sido processadas informações que reduzissem as condições de incerteza, ditadas pela interação do sistema-emprêsa e o ambiente externo.

O sistema de informações não se limita à coleta, análise e processamento de informações externas; avalia também informações internas decorrentes da operação da própria emprêsa.

Um sistema de informações deve ser estruturado como um processo contínuo de comunicações, cujos inputs são informaçరes internas e cujos outputs são informações processadas para a tomada de decisões. 


\subsection{OBJETIVOS}

$O$ objetivo central do sistema de informações deve ser o de desenvolver e expandir as bases para as decisões administrativas. Sugere-se que êsse sistema seja considerado como um órgão de staff, não apenas para as tarefas de planejamento pròpriamente ditas, como também para os demais setores da emprêsa, os quais poderão dêle receber ou solicitar informações.

Mais especificamente, o sistema de informações deverá fornecer informações, processadas mediante solicitação explícita, ou não, de outros. Estas informações têm como objetivo prover os executivos com dados para que o trinômio

$$
\text { Informação Decisão }
$$$$
\text { Ação }
$$

possa ser eficientemente processado (Jay Forrester).

As decisões de caráter programado, bem como aquelas de caráter não programado também se utilizam de informações. Em ambos os casos as decisões administrativas poderão ser mais eficientes e efetivas pela existência de informações.

Para as decisões programadas, as informações oferecem parâmetros de contrôle, enquanto que, para as decisões não programadas, o executivo pode reduzir o grau de julgamento intuitivo, que seria necessário para êste tipo de decisão, caso não houvesse informações sôbre as mesmas (Herbert Simon).

Finalmente, o sistema de informações possibilita a criação de bases sólidas para as funções de planejamento e contrôle (Anthony).

\section{Informaçø̃es}

\subsection{CLASSIFICAÇÃO}

As informações coletadas e processadas deverão ser classificadas segundo os seguintes critérios:
a) internas
b) externas
c) por origem na organização
d) por origem em ( Itras instituições 
e) planejadas

f) não planejadas

g) contínuas

h) intermitentes

i) por intervalos de tempo (CML prazos)

j) por setores organizacionais, etc.

A classificação de informações, também conhecida com a denominação de taxonomia, é um processo ordenado de coleta, análise, observando-se as características específicas da emprêsa e a natureza das informações pròpriamente ditas.

A classificação das informações, que é a primeira fase do processo, tem como objetivo não apenas o reconhecimento e a avaliação das informações, mas também fornecer bases para o funcionamento do sistema de informações, que disciplina e melhora o padrão preexistente do fluxo de informações na emprêsa.

\subsection{COLETA}

Esta fase deve ser concebida como um processo contínuo cujo objetivo é o de recolher dados primários (Raw Data) que sejam de origem interna e/ou externa à emprêsa.

Estes dados, após avaliação preliminar, são ordenados, de acơrdo com o esquema geral de classificação, definido no item 2.1.

\subsection{PROCESSAMENTO}

As tarefas de processamento de informações são necessárias para a triagem inicial e também para a posterior avaliação dạs características das mesmas.

O processamento de informaçס̃es tem dimensర̃es mais amplas do que uma simples análise preliminar, pois esta fase deve estender-se à determinação dos setores (unidades de decisão) que devem ou necessitam receber os dados. Neste particular é importante a forma e a frequêencia, com que as informaçóes processadas serão transmitidas através da organização. 


\subsection{CODIFICAÇÃO}

Duas dimensões são relevantes para o processo de codificação das informações, o qual deve apresentar os seguintes atributos:

a) codificação coerente com os parâmetros de classificação adotados;

b) codificação com ampla flexibilidade.

\subsection{ARQUIVAMENTO}

O sistema de informações, além de oferecer um fluxo contínuo de comunicações ordenadas para a emprêsa, representa também um pool de dados que podem ser requisitados em fases futuras; em conseqüência dêstes fatôres as informações deverão ser objeto de exame por parte dos executivos da emprêsa, quando da implantação do sistema.

\subsection{RETRIEVAL}

Define-se esta fase do processo de operação do sistema de informações como o momento no qual, através de uma unidade de exposição (display unit), solicita-se e obtém-se uma informação ou um conjunto de informações.

A eficiência de um processo desta natureza é medida em função da rapidez e da qualidade, com que as informaçóes solicitadas são recebidas da fonte de informações.

\section{Organização do Sistema}

\subsection{PROGRAMA DE ORGANIZAÇAO}

Um programa minucioso para a organização de um sistema de informações pode ser esquematizado da seguinte maneira:

- definir e ordenar as tarefas a serem executadas para a implantação do sistema;

- elaborar um cronograma preliminar com a sequêencia das tarefas;

- transformar o cronograma preliminar em uma rêde PERT, determinando-se, a seguir, o CPM; 
- definir e planejar as tarefas de implantação, atribuindo-se sua responsabilidade aos executivos da emprêsa.

- iniciar a operação em fase experimental.

\subsection{RECURSOS HUMANOS}

Nesta fase de elaboração do anteprojeto não seria possível entrar em pormenores de ordem orçamentária, quanto aos dispêndios necessários ao funcionamento do sistema de informações.

E possível, entretanto, definir os recursos humanos que são necessários ao seu funcionamento:

- 1 chefe de departamento

- 1 secretária

- 2 analistas (EDP)

- 1 arquivista

- 1 bibliotecária

\subsection{IMPLANTAÇĀO}

Após a análise do anteprojeto recomenda-se que a fase de implementação seja imediatamente iniciada. As eventuais e necessárias correções do plano de operações serão definidas depois do periodo experimental, já examinado.

\section{Operação do Sistema}

\subsection{MODELO}

Diversos modelos e diagramas de fluxo para a operação do sistema de informaçóes podem ser utilizados. Em anexo, apresentamos um exemplo.

\subsection{INPUT DE DADOS}

O sistema de informações deverá funcionar como em sistema de circuito aberto, o qual recebe dados de tôda a organização, os quais, após o devido processamento, são transmitidos e/ou arquivados. 
Segundo êste critério todos os setores da emprêsa deverão reunir dados primários e enviá-los ao sistema de informaçóes; êstes dados representam inputs do sistema.

\subsection{OUTPUT DE DADOS}

Todos os dados primários e o processamento representam, em última análise, outputs do sistema, ou seja, informaçб̃es. Nota-se que se pretende dar ao sistema de informaçóes uma configuração integral de um sistema completo de input-output (complete inputoutput system).

O esquema abaixo ilustra o procedimento recomendado para as operações do sistema de informações.

Este esquema define, ao mesmo tempo, as funções de operação e contrôle do sistema elaborado e recomendado neste comentário.

\subsection{OPERAÇAOO E CONTROLE}

FIGURA 1: Fluxo do Processamento de Informaçōes.

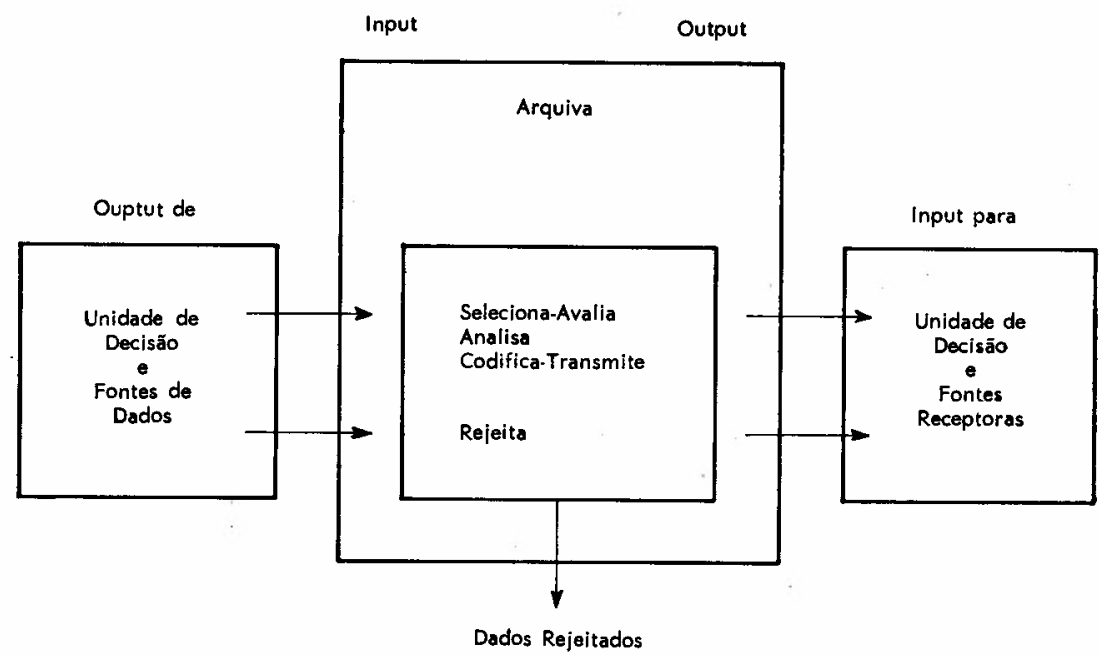

O sistema de informaçóes deve efetuar todos os serviços de informação, servindo a tôdas as unidades de decisão da emprêsa. Agirá como um sistema integrado de input-output. Os inputs - 
que são outputs das unidades de decisão - são dados primários ou pedidos de informação. Similarmente, os outputs são as informações, sejam elas solicitadas ou automàticamente comunicadas.

\section{Bibliografia}

DEARDEN, John. Management of Information Systems - Text and Cases. Irwin, 1969. 